\title{
Quantitative Angiographic Comparison of the Immediate Success of Coronary Angioplasty, Coronary Atherectomy and Endoluminal Stenting
}

\author{
David W. M. Muller, MBBS, Stephen G. Ellis, MD, Darrell L. Debowey, MS, and Eric J. Topol, MD
}

Coronary atherectomy and coronary stenting effectively reduce the severity of coronary artery stenom ses, but direct comparisons of these interventions with conventional balloon angioplasty have not been performed. To compare the immediate efficacy of these 3 interventions, the angiographic morphology and the severity of the residual coronary stenosis were quantitatively evaluated in 18 patients undergoing coronary atherectomy and in 21 patients treated by endoluminal coronary stenting. Each of these groups of patients was compared with a matched group of coronary angioplasty patients selected from a large, computerized database. The variables matched included patient age and sex, lesions site and severity, and lesion complexity. Both coronary atherectomy and coronary stenting more effectively reduced the severity of the coronary stenosis when compared with balloon angioplasty. The luminal diameter stenosis was roduced from $\mathbf{6 9} \pm 10$ to $22 \pm \mathbf{2 0 \%}$ in the atherectomy group compared with a reduction from $74 \pm$ 11 to $44 \pm 14 \%$ in the matched coronary angioplasty population ( $p=0.008$ ). Similarly, the luminal diameter stenosis was reduced from $77 \pm 11$ to $26 \pm 12 \%$ in the stented group compared with a reduction from $81 \pm 10$ to $42 \pm 14 \%$ in the matched coronary angioplasty group $(p=0.014)$. In addition, moderate or severe coronary dissections were noted more frequently in the coronary angioplasty groups than in their respective atherectomy and stent groups ( 0 vs $33 \%, p=0.008$, and 5 vs $19 \%, p=0.15$, respectively). These data suggest that, in selected patients, both coronary atherectomy and coronary stenting more effectively reduce the severity of coronary stenoses when compared with conventional balloon angioplasty and that this may be achieved with a lower risk of medial dissection.

(Am J Cardiol 1990;66:938-942) ince its introduction by Gruentzig et al in 1979, percutaneous transluminal coronary angioplasty 1 (PTCA) has become a well-characterized technique for the relief of critical coronary artery stenoses. The procedure remains limited, however, by the risk of coronary dissection and abrupt closure of the dilated vessel in 3 to $5 \%, 2,3$ and by recurrent stenosis at the site of dilatation. ${ }^{4-8}$ Coronary atherectomy and endoluminal stenting are 2 alternative interventions that have the potential to overcome these limitations. Directional coronary atherectomy ${ }^{9}$ physically removes obstructive atheromatous tissue, and endovascular stenting ${ }^{10}$ maintains luminal diamcter by compressing the artcrial wall and preventing elastic recoil of the dilated arterial segment. By achieving a smoother, less disrupted arterial wall, these devices may reduce the stimulus for medical smooth muscle proliferation and coronary arterial restenosis. Therefore, to compare the immediate efficacy of these 2 procedures with that of conventional balloon angioplasty, the angiographic morphology and the severity of the residual, postprocedural stenosis were determined in a group of patients undergoing coronary atherectomy, in a group undergoing endoluminal stenting and in matched groups undergoing conventional balloon angioplasty.

\section{METHODS}

Between August 1988 and March 1989, 18 patients underwent coronary atherectomy with the Simpson directional coronary atherectomy device. ${ }^{9}$ This over-thewire device consists of a catheter-mounted, metallic capsule (Figurc 1), and a central metallic blade that rotates at 2,500 revolutions $/ \mathrm{min}$. The open side of the capsule is held against the diseased arterial wall by low pressure inflation of a balloon mounted on the opposite side of the device. Atheromatous tissue is removed by the rotating blade, which is slowly advanced, pushing the excised tissue forward into a distal, conical collecting chamber. Each arterial quadrant is sequentially shaved. The device is then removed and atheromatous fragments are retrieved from the distal chamber. During the study period, patients were considered eligible for atherectomy if they had a coronary stenosis in a relatively straight segment of 1 of the 3 major epicardial vessels, without proximal tortuosity or heavy calcification. Each patient received oral aspirin $\geq 24$ hours before the procedure. Intravenous heparin $(15,000 \mathrm{IU})$ was given after the initial guiding angiograms and further doses of 5,000 IU were given each hour to maintain anticoagulation during the procedure.
From the Division of Cardiology, Department of Internal Medicine, University of Michigan Medical Center, Ann Arbor, Michigan 48109. Manuscript received February 13, 1990; revised manuscript received and accepted June 1, 1990.

Address for reprints: Eric J. Topol, MD, Division of Cardiology, University of Michigan Medical Center, B1 F245, 1500 East Medical Center Drive, Ann Arbor, Michigan 48109-0022. 


\begin{tabular}{|c|c|c|c|c|}
\hline & $\begin{array}{l}\text { Atherectomy } \\
(n=18)\end{array}$ & $\begin{array}{l}\text { PTCA-Atherectomy } \\
(n=18)\end{array}$ & $\begin{array}{l}\text { Stent } \\
(n=21)\end{array}$ & $\begin{array}{l}\text { PTCA-Stent } \\
(n=21)\end{array}$ \\
\hline Age $(y r s)^{*}$ & $57 \pm 12$ & $56 \pm 12$ & $58 \pm 10$ & $56 \pm 10$ \\
\hline $\operatorname{Sex}(M / F)$ & $16 / 2$ & $16 / 2$ & $16 / 5$ & $16 / 5$ \\
\hline Prior PTCA & 10 & 4 & 12 & 4 \\
\hline \multicolumn{5}{|c|}{ Stenosis site (proximal/mid/distal) } \\
\hline Left anterior descending & $10 / 6 / 0$ & $8 / 8 / 0$ & $3 / 5 / 0$ & $3 / 5 / 0$ \\
\hline Right & $0 / 0 / 2$ & $0 / 0 / 2$ & $3 / 7 / 0$ & $2 / 7 / 1$ \\
\hline Circumflex & $0 / 0 / 0$ & $0 / 0 / 0$ & $1 / 1 / 1$ & $2 / 0 / 1$ \\
\hline \multicolumn{5}{|l|}{ Initial TIMI grade flow } \\
\hline 3 & 12 & 8 & 10 & 8 \\
\hline 2 & 6 & 9 & 6 & 9 \\
\hline 1 & 0 & 1 & 4 & 3 \\
\hline 0 & 0 & 0 & 1 & 1 \\
\hline \multicolumn{5}{|c|}{ Initial morphology (ACC/AHA Classification) } \\
\hline Type A & 10 & 8 & 10 & 12 \\
\hline Type B & 8 & 10 & 11 & 8 \\
\hline Type C & 0 & 0 & 1 & 1 \\
\hline \multicolumn{5}{|l|}{ Absolutc diameter $(\mathrm{mm})^{*}$} \\
\hline Initial & $1.0 \pm 0.5$ & $0.7 \pm 0.3$ & $0.7 \pm 0.3$ & $0.6 \pm 0.3$ \\
\hline Final & $2.5 \pm 0.6$ & $1.6 \pm 0.5$ & $2.4 \pm 0.4$ & $1.7 \pm 0.4$ \\
\hline Change & $1.5 \pm 0.6$ & $0.9 \pm 0.5$ & $1.0 \pm 0.5$ & $1.2 \pm 0.5$ \\
\hline
\end{tabular}

Over the same period, Palmaz-Schatz coronary stents ${ }^{10}$ were inserted into the stenosed coronary arterial segments of 21 patients. Indications for coronary stenting were similar to those for coronary atherectomy. After balloon dilatation of the diseased segment, the cylindrical, stainless steel wire mesh stents (Figure 2) were delivered on a conventional coronary angioplasty balloon that was inflated to expand the stent to the required size. The design of the stent ensures that, once dilated, the device retains its expanded form, preventing elastic recoil of the arterial wall. Each patient received oral aspirin and dipyridamole, intravenous dextran and $15,000 \mathrm{IU}$ intravenous heparin before the insertion of the stent, and intravenous heparin was continued for a period of $\geq 24$ hours after the procedure. Neither intravenous nor intracoronary nitroglycerin was given routinely during coronary atherectomy or coronary stenting.

The postprocedural angiographic characteristics of the 18 atherectomy and 21 stented patients were compared with those of matched populations (PTCA-atherectomy and PTCA-stent, respectively) selected from a large, elective coronary angioplasty database. The computer-matched variables included patient agc and sex, and the site and severity of the coronary stenosis. Consideration was also given to whether the stenosis was a new lesion or a recurrent stenosis following a previous coronary intervention. However, relatively few procedures in the angioplasty database were performed on recurrent stenoses, thus limiting the possibility of a close match for this variable. After identification of several potential patient matches, an attempt was also made, by comparison of the baseline angiograms, to match for lesion complexity based on the lesion length, angulation and degree of proximal tortuosity. Patients from the database were not considered for matching if coronary angioplasty failed to reduce the target stenosis to $<50 \%$ luminal diameter stenosis by visual estimate. No attempt was made to match the atherectomy group with the stent group or to comparc their respective outcomes directly.

Analysis of the immediate angiographic result of each procedure was performed using an automated, computerized edge-detection algorithm (Artrek) that

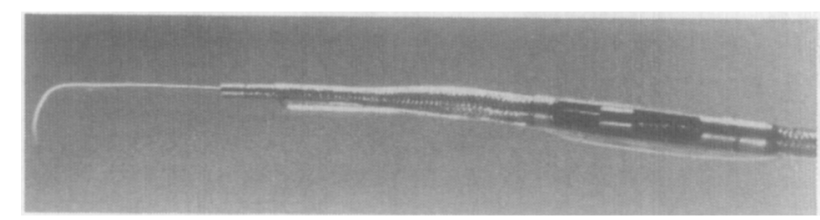

FIGURE 1. The Simpson directional coronary atherectomy device.

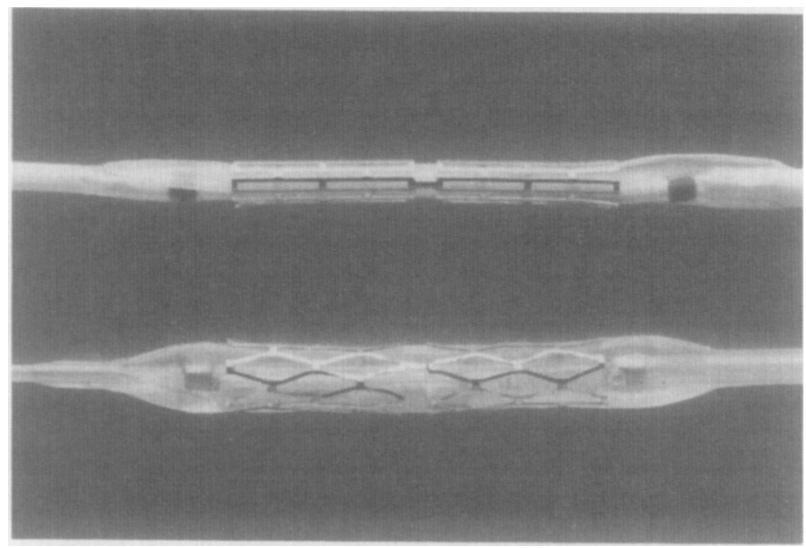

FIGURE 2. The Palmaz-Schatz coronary stent before and after balloon inffation. 
has been previously described and validated. ${ }^{11}$ Preprocedural coronary stenosis severity was quantitated in the single tightest angiographic projection by a single observer unaware of which procedure was subsequently performed. Postprocedural analysis was performed in the identical projection as the initial measurement by the same observer blinded, to the extent possible, from treatment modality. Coronary arterial morphology at the site of intervention was also recorded. Acute coronary dissection was graded as being absent, mild (if a minor disruption occurred in the endothelial contour), moderate (if a linear extraluminal opacity or intraluminal filling defect was apparent) or severe (if a spiral dissection extended beyond the length of the dilated lesion or resulted in compromised coronary flow).

Statistics: All data are expressed as mean \pm 1 standard deviation. Comparison of the severity of the residual stenosis between the groups was performed using the unpaired Student $t$ test and differences were considered to be statistically significant at $p<0.05$. The incidence of acute dissection was compared using the chisquare test.

\section{RESULTS}

Baseline demographic and angiographic characteristics of the atherectomy group, the stent group and of the 2 respective matched angioplasty groups are listed in Table I. The groups were well matched for age, sex,

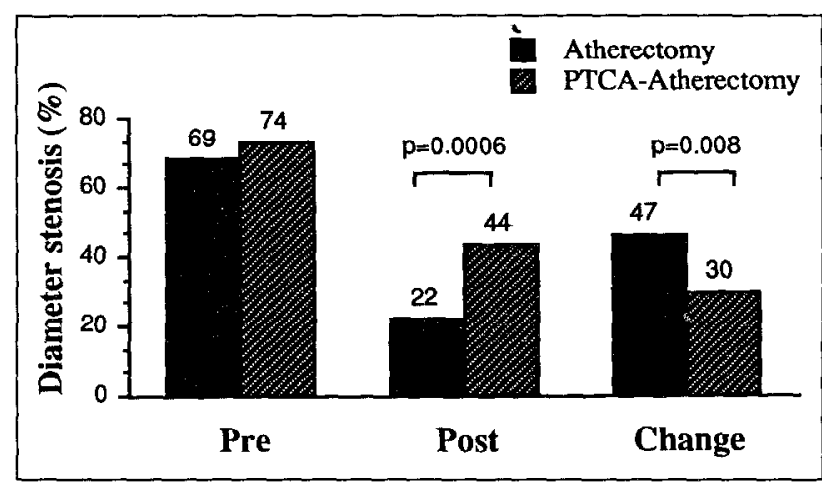

FIGURE 3. Comparison of the coronary luminal diameter stenosis before and after intervention in the atherectomy group and its matched angioplasty group (PTCA-Atherectomy).

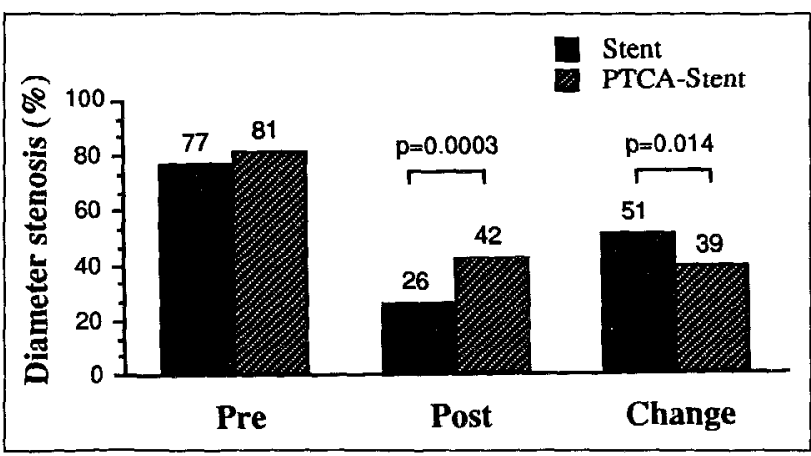

FIGURE 4. Comparison of the coronary luminal diameter stenosis before and after intervention in the stented group and in the matched angioplasty group (PTCA-Stent). lesion site and initial lesion morphology. However, a noticeably higher proportion of the lesions treated with the newer devices were recurrent stenoses following prior coronary angioplasties. Of the 18 atherectomy patients, 10 had had a prior angioplasty compared with 4 of the matched angioplasty group. Similarly, 12 of the 21 stent patients had had prior angioplasty compared with 4 of the matched group. This reflects early referral patterns and selection criteria for stent implantation and atherectomy.

Before the interventional procedure, the severity of the coronary stenosis was similar in each of the groups (Figures 3 and 4). Lesion morphology (American College of Cardiology/American Heart Association classification) was also similar in the matched groups, but a slightly higher proportion of each angioplasty group had coronary flow less than Thrombolysis in Myocardial Infarction grade 3 (Table I). Both atherectomy and coronary stenting resulted in significantly greater improvements in coronary luminal diameter than was achieved in their respective matched angioplasty populations. The postatherectomy luminal diameter stenosis was reduced to $22 \pm 20 \%$ compared with $44 \pm 14 \%$ in the angioplasty group $(p=0.0006)$ (Figurc 3$)$, and the absolute diameter was increased by $1.5 \pm 0.6 \mathrm{~mm}$ compared with $0.9 \pm 0.5 \mathrm{~mm}(\mathrm{p}<0.003)$ (Table I). Similarly, the final luminal diameter stenosis in the stented patients was $26 \pm 12 \%$ compared with $42 \pm 14 \%$ in the corresponding angioplasty group $(\mathrm{p}=0.0003)$ and the absolute diameter was increased by $1.6 \pm 0.5 \mathrm{~mm}$ compared with $1.2 \pm 0.5 \mathrm{~mm}(\mathrm{p}<0.009)$. Importantly, there did not appear to be any evidence of procedurerelated coronary vasoconstriction. Although intracoronary nitroglycerin was not given routinely, there were no significant changes in the caliber of the proximal reference segment of the treated coronary artery in the atherectomy group $(3.1 \pm 0.6$ vs $3.2 \pm 0.5 \mathrm{~mm})$, the stented group $(3.2 \pm 0.5 \mathrm{vs} 3.4 \pm 0.9 \mathrm{~mm})$ or in the PTCA-atherectomy and PTCA-stent groups $(2.8 \pm 0.6$ vs $2.8 \pm 0.5 \mathrm{~mm}$, and $3.0 \pm 0.5$ vs $3.0 \pm 0.5 \mathrm{~mm}$, respectively). The incidence of moderate or severe dissection was, however, significantly higher after balloon angioplasty than after atherectomy (0 vs $33 \% ; p=0.008)$ (Figure 5). Dissections of at least moderate severity were also less frequent after the stent procedures than in

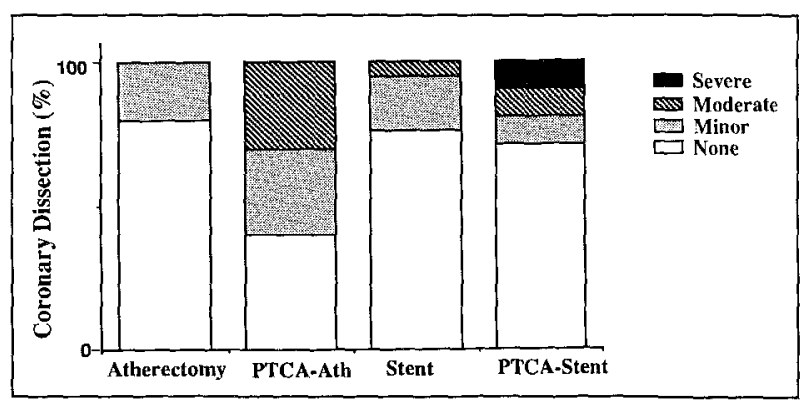

FIGURE 5. Incidence and severity of postprocedural coronary dissection in the atherectomy and stented groups and in their respective matched angioplasty groups. Ath $=$ atherectomy; other abbreviations as in Figures 3 and 4. 
the corresponding PTCA group, but the difference did not reach statistical significance ( 5 vs $19 \%, \mathrm{p}=0.15$ ).

\section{DISCUSSION}

Immediate angiographic results: The principal finding of this study was that both directional coronary atherectomy and endovascular stenting achieved a greater reduction in the severity of obstructive coronary stenoses than was achieved in matched populations using conventional balloon angioplasty. In addition, use of these devices was associated with a lower incidence of coronary arterial dissection. Although the study was not designed to compare coronary atherectomy directly with stenting, there did not appear to be any substantial difference in the angiographic results of the 2 interventions.

The relatively high residual stenosis and high incidence of dissection after coronary angioplasty in this study are consistent with the known mechanisms by which balloon angioplasty improves coronary luminal dimensions and with the associated pathologic changes observed early after the procedure. These mechanisms include stretching of the arterial wall, endothelial disruption, plaque fracture and medial dissection. ${ }^{12} 14$ Similar pathologic changes undoubtedly occur during the insertion of coronary stents, but the disrupted layers of the arterial wall are splinted by the meshwork of the device. This may allow the safe use of larger angioplasty balloons and higher inflation pressures during stent implantation, a factor that may have contributed to the better immediate results noted in this study. Coronary atherectomy, on the other hand, appears to depend less on stretching of the vascular wall and more on the excision of atheromatous material. During the immediate post-angioplasty period, some of the initial increase in luminal diameter and cross-sectional area may be diminished by passive, elastic recoil of the arterial wall or by coronary vasoconstriction, ${ }^{15}$ mediated by endothelially derived vasoconstrictive factors. ${ }^{16}$ Both of these factors are effectively minimized by endovascular stenting. Whether coronary atherectomy also reduces the propensity for elastic recoil and coronary vasoconstriction by removing or injuring medial smooth muscle has not been evaluated.

Vascular disruption: The greater improvement in coronary luminal dimensions after coronary stenting and coronary atherectomy was associated with a lower incidence of coronary dissection than was apparent after conventional balloon angioplasty. This suggests that these interventions may reduce the likelihood of acute closure of the vessel and therefore increase the safety of the procedure. Coronary stents have, in fact, been used successfully both to treat and to prevent acute closure after balloon angioplasty-induced intimal dissection. ${ }^{17}$

Immediate angiographic results and restenosis: Whether the apparently superior immediate results achieved with these new devices will be associated with a reduction in the incidence of recurrent stenosis is not yet clear. The factors that trigger medial smooth muscle cell migration and proliferation remain poorly under- stood. The incidence of restenosis after balloon angioplasty has been correlated with the severity of the residual coronary stenosis and the presence of a residual translesional gradient. ${ }^{4,18}$ Deep arterial injury that exposes a large surface area of collagen may also increase the stimulus for smooth muscle cell proliferation. ${ }^{19} \mathrm{Con}$ ceivably, endovascular stents may reduce the likelihood of restenosis by "sealing" intimal flaps and minimizing the amount of exposed collagen. Furthermore, the greater caliber achieved after stent implantation may minimize the functional importance of subsequent intimal proliferation. ${ }^{20}$ Conversely, atherectomy grcatly increases the exposure of medial (and occasionally adventitial) collagen and may actually increase the likelihood of restenosis. At this point, the pathophysiology of restenosis after the newer interventions remains conjectural. Preliminary data suggest, however, that neither device will eliminate this problem. ${ }^{20,21}$

Study limitations: The major limitation of this study is that it is a retrospective, nonrandomized study. Although the 2 groups are well matched for several demographic and angiographic variables, differences between them may be important. For example, a greater proportion of the lesions treated by stenting or atherectomy were recurrent stenoses following previous balloon dilatation. The inherently different underlying pathologic substrates between new and recurrent stenoses may have influenced the ease of the procedure and the likelihood of acute complications, ${ }^{3}$ a factor that, in this study, would favor the atherectomy and stent groups. Second, this study was a comparison of successful coronary interventions and may not be fully representative of the total population on whom percutaneous interventions are attempted. Finally, because of the relatively small number of patients treated with the newer devices, it was not possible to match the stent population with the population undergoing coronary atherectomy. For this reason, no direct comparison can be made between these 2 procedures. These considerations suggest that a randomized, controlled clinical trial is warranted to compare the immediate angiographic results and the long-term efficacy of each of these 3 interventions.

\section{REFERENCES}

1. Gruentzig AR, Senning A, Siegenthaler WE. Non-operative dilatation of coronary artery stenoses: percutaneous transluminal coronary angioplasty. $N$ Engl J Med 1979;301:61-68.

2. Detre K, Holubkov R, Kelsy S, Bourassa M, Williams D, Holmes D Jr, Dorros G, Faxon D, Myler R, Kent K, Cowley M, Cannon R, Robertson T, and Coinvestigators of the National Heart, Lung, and Rlond Institute's Percutaneous Transluminal Coronary Angioplasty Registry. One-year follow-up results of the 1985 1986 Second National Heart, Lung, and Blood Institute percutaneous transluminal coronary angioplasty registry. Circulation 1989;80:421-428.

3. Bredlau CE, Roubin $G$, Leimgruber $P$, Douglas J, King S, Gruentzig A. Inhospital morbidity and mortality in patients undergoing elective coronary angioplasty. Circulation 1985;72:1044-1052.

4. Leimgruber PP, Roubin GS, Hollman J, Cotsonis GA, Meier B, Douglas JS King SB, Gruentzig AR. Restenosis after successful coronary angioplasty in patients with single vessel disease. Circulation 1986;73:710-717.

5. Schwartz L, Bourassa MG, Lesperance J, Aldridge IIE, Kazim F, Salvator VA, Henderson M, Bonan R, David PR. Aspirin and dypiridamole in the prevention of restenosis after percutaneous transluminal coronary angioplasty. $\mathrm{N} \mathrm{Engl} J$ Med 1988;318:1714-1719.

6. Grigg LE, Kay TWH, Valentine PA, Larkins R, Flower DJ, Manolas EG, 
O'Dea K, Sinclair AJ, Hopper JL, Hunt D. Determinants of restenosis and lack of effect of dietary supplementation with eicosapentanoic acid on the incidence of coronary restenosis after angioplasty. J Am Coll Cardiol 1989;13:665-672 7. Ellis SG, Roubin GS, Wilentz J, Douglas JS, King SB. Effect of 18-24 hour heparin administration for prevention of restenosis after uncomplicated coronary angioplasty. Am Heart $J$ 1989; 1 17:777-782

8. Corcus T, David PR, Val PG, Renkin J, Dangoisse V, Rapold HG, Bourassa MG. Failure of diltiazem to prevent restenosis after percutaneous translumina coronary angioplasty. Am Heart $J$ 1985;109:926-931.

9. Hinohara T, Selmon MR, Robertson GC, Braden L, Simpson JS. Directional atherectomy: new approaches for treatment of obstructive coronary and peripheral vascular disease. Circulation 1990;81(suppl IV):IV-79-IV-91.

10. Schatz RA. A view of vascular stents. Clrculation 1989;79:445-457.

11. Mancini GBJ, Simon SB, McGillem MJ, LeFree ML, Friedman HZ, Voge RA. Automated quantitative coronary angiography; morphologic and physiologic validation in vivo of a rapid digital angiographic method. Circulation 1987, 75:452-460.

12. Waller BF. "Crackers, breakers, stretchers, drillers, scrapers, shavers, burners, welders, and melters"--The future treatment of atherosclerotic coronary artery disease? A clinical-morphological assessment. J Am Coll Cardiol 1989; 13:969-987.

13. Soward AL, Essed CE, Serruys PW. Coronary arterial findings after accidental death immediately after successful percutaneous transluminal coronary angioplasty. Am J Cardiol 1985;56:794-795.
14. Waller BF. The eccentric coronary atherosclerotic plaque: morphologic observations and clinical relevance. Clin Cardiol 1989;12:14-20.

15. Hollnan J, Austin GE, Gruenlzig AR, Duuglas JS, King SB. Coronary artery spasm at the site of angioplasty in the first 2 months after successful percutaneous transluminal coronary angioplasty. $J$ Am Coll Cardiol 1983;1 1039-1045.

16. Fischell TA, Nellessen U, Johnson DE, Ginsburg R. Endothelium-dependent arterial vasoconstriction after balloon angioplasty. Circulation 1989;79:899-910. 17. Sigwart U, Urban P, Golf S, Kaufmann U, Imbert C Fisher A, Kappenberger L. Emergency stenting for acute occlusion after coronary balloon angioplasty. Circulation 1988;78:1121-1127.

18. Mata LA, Bosch X, David PR, Rapold HJ, Corcos T, Bourassa MG. Clinical and angiographic assessment 6 months after double vessel percutaneous coronary angioplasty. J Am Coll Cardiol 1985;6:1239-1244.

19. Chesebro JH, Lam JYT, Badimon L, Fuster V. Restenosis after arterial angioplasty: a hemorrheologic response to injury. Am J Cardiol 1987;60:10B$16 \mathrm{~B}$.

20. Serruys PW, Beatt KJ, Strauss BH, Bertrand ME, Puel J, Rickards AF Meier B, Kappenberger L, Sigwart U. Quantitative angiographic follow-up of coronary stents: report on the initial 105 patients from March 1986 to January 1988. N Engl J Med 1990; in press.

21. Hinohara T, Rowe $M$, Sipperly ME, Johnson D, Robertson G, Selmon M, Leggett J, Simpson J. Restenosis following directional atherectomy of native coronary arteries (abstr). $J$ Am Coll Cardiol 1990;15:196A. 